\title{
The Temperature Field Pattern of Small Caliber Automatic Gun
}

\author{
Da Xu' ${ }^{a}$, Ye Luo ${ }^{b}$ and Wenbo Fan ${ }^{c}$
}

Department of Arms Engineering, Academy of Armored Force Engineering, Beijing 100072, China

axyxd@sina.com, ${ }^{\mathrm{b}} 1518391486 @ q q . c o m,{ }^{c} 1976257507 @ q q . c o m$

Keywords: temperature field; chromium layer; automatic gun

Abstract: To study the temperature distribution characteristics of small artillery barrel under different shoot conditions, this article first establishes the propellant gas temperature equations during the interior ballistic period and the aftereffect period, based on which the initial conditions of heat transfer is determined; then analyzes the heat transfer coefficient of bore-surface during the interior ballistic period, based on which heat transfer boundary is clarified; and then establishes the heat transfer model of artillery barrel based on the theory of heat transfer, solve the model on basis of the finite difference method; finally analyzes the temperature field distribution and variation law under the single and repeating firing conditions, taking the $30 \mathrm{~mm}$ barrel of chrome plating as an example and draw the conclusion that the temperature gradient near the chromium layer is not notable, which laid the foundation for the research on the life of small caliber barrel next.

\section{Introduction}

The gun is a gun firing weapon, in which the shell is launched taken gunpowder as the energy [1]. During the shoot process, there are three reasons leading to the bore shape and size change, namely thermal, chemical and mechanical factors, practice has proved that the thermal has the largest effect on erosion and wear of the bore [2-4]. The heat transfer will cause softening and thermal ablation, the gun barrel deformation of the projectile then will have a significant impact on the muzzle velocity, firing precision, firing frequency and barrel strength [5-7]. So the body barrel heat transfer analysis is the premise to reveal and calculate the mechanism of barrel wear and erosion, and to study the life of barrel. For the inner chrome barrel, due to thermal conductivity chromium layer and substrate steel of different rates, analysis of the interface heat transfer analysis for the chromium layer and the failure mechanism is off important significance.

Based on the above analysis, the $30 \mathrm{~mm}$ small caliber gun barrel is taken as an example to simulate the heat transfer process of barrel combined with heat transfer theory, then the temperature field of the single and subsequent firing process is obtained and the temperature distribution during single and sequent process of barrel along the radial is analyzed. The research results provide the theoretical basis for the study of small caliber gun $30 \mathrm{~mm}$ analysis and life prediction of the ablation mechanism of chromium plated gun barrel.

\section{The heat transfer model of gun barrel}

We respectively definite $T_{1}, T_{2}, T_{\mathrm{s} 1}, T_{\mathrm{s} 2}$ as the gunpowder gas temperature, the environment gas temperature, the bore and the outer surface temperature of barrel, $h_{1}$ and $h_{2}$ respectively corresponding convective gas flow and the heat transfer coefficient of air environment.

\section{The heat transfer control equation of gun barrel}

According to the theory of heat transfer, the governing differential equations of the unsteady one dimensional radial heat transfer in the cylindrical coordinate system are obtained:

$$
\frac{\partial T}{\partial t}=a\left(\frac{\partial^{2} T}{\partial r^{2}}+\frac{1}{r} \frac{\partial T}{\partial r}\right) \quad\left(r_{0} \leq r \leq R, t \geq 0\right)
$$


In the formula, $T$ is the chamber bore temperature $(\mathrm{K}) ; t$ is the time $(\mathrm{s}) ; a$ is the body barrel material temperature coefficient $\left(\mathrm{m}^{2} / \mathrm{s}\right) ; r$ is radius of a point within the barrel $(\mathrm{m}) ; r_{0}$ is the inner barrel bore radius; $\mathrm{R}$ is the outer bore radius of the body.

\section{The heat transfer boundary of gun barrel}

1) The heat transfer boundary of inner bore

According to the hypothesis, the influence of radiation heat is neglected, and the boundary conditions of heat transfer in the inner bore are obtained:

$$
\left.\lambda \frac{\partial T}{\partial r}\right|_{r=r_{0}}+\left.h_{1}\left(T_{g}-T\right)\right|_{r=r_{0}}=0
$$

In the formula, $\lambda$ is the heat conduction coefficient of the body barrel material, $h_{1}$ is the heat transfer coefficient of the gas and the inner bore, and the $T_{\mathrm{g}}$ is the gas temperature of the chamber bore.

2 ) The heat transfer boundary of Outer bore

According to the assumed conditions, the inner bore of the outer bore of the body and the body of the firing interval is exchanged with the environment by natural convection:

$$
\left.\lambda \frac{\partial T}{\partial r}\right|_{r=R}+\left.h_{2}\left(T-T_{0}\right)\right|_{r=R}=0
$$

In the formula, $h_{2}$ is the heat transfer coefficient of air flow in the chamber and the chamber bore $T_{0}$ is the temperature of the surrounding environment before firing.

\section{Initial conditions of heat transfer}

At the first shoot, the initial conditions for the heat transfer temperature of the surrounding environment before firing; change after firing when the initial conditions of heat transfer, is no longer the ambient temperature, but the end barrel temperature of the last projectile shoot, that is to say:

The first shoot: $T=T_{0}$

Sequent shoot: $T=f(r) f(r)$ is the radial temperature distribution of a projectile firing at the end.

\section{Solution of heat transfer equation and numerical simulation process}

The establishment of the movement equation of temperature and aftereffect of gunpowder gas projectile in bore,

At the shooting interval period, using the same analysis method to calculate the convective heat transfer coefficient in the bore; at the aftereffect stage we take the average value of the convective heat transfer coefficient and corresponding convection at the interval time of interior ballistic projectile during the shooting.

The differential equations were obtained by using the finite difference method to solve the difference equations of the inner node and the boundary node in the radial direction and the time $\mathrm{t}$.

Internal node temperature equation:

$$
T_{i^{\prime}}^{j+1}=F_{0}\left(1+\frac{\Delta r}{2 r_{i^{\prime}}}\right) T_{i^{\prime}+1}^{j}+\left(1-2 F_{0}\right) T_{i^{\prime}}^{j}+F_{0}\left(1-\frac{\Delta r}{2 r_{i^{\prime}}}\right) T_{i^{\prime}-1}^{j}
$$

In the formula, $F_{0}=a \Delta t /(\Delta r)^{2}$ is the Fourier Number for the body barrel material, $r_{i}$ is the radius of the $i$ th node, the $t_{\mathrm{j}}$ is the $j$ th time node, $\Delta r$ is the radial section interval, $\Delta t$ is the time interval. Inner bore temperature equation:

$$
T_{0}^{j+1}=\left[1-\frac{2 a \Delta t}{\Delta r^{2}}\left(1+\frac{h_{1}^{j} \Delta r}{\lambda}\right)\right] T_{0}^{j}+\frac{2 a \Delta t}{\Delta r^{2}} T_{1}^{j}+\frac{2 a \Delta t}{\Delta r^{2}} \frac{h_{1}^{j} \Delta r}{\lambda} T_{g}^{j}
$$

Outer bore temperature equation:

$$
T_{m}^{j+1}=\left[1-\frac{2 a \Delta t}{\Delta r^{2}}\left(1+\frac{h_{2}^{j} \Delta r}{\lambda}\right)\right] T_{m}^{j}+\frac{2 a \Delta t}{\Delta r^{2}} T_{m-1}^{j}+\frac{2 a \Delta t}{\Delta r^{2}} \frac{h_{2}^{j} \Delta r}{\lambda} T_{0}
$$


In order to facilitate the analysis of temperature field distribution along the radial direction of the barrel body, in the initial section of the barrel rifling along the radial direction from 5 nodes, numbered $\mathrm{A} \sim \mathrm{E}$; the $\mathrm{A}$ in the inner bore; $\mathrm{B}$ in chromium layer and steel substrate interface, from the inner bore of the $0.05 \mathrm{~mm}$; $\mathrm{E}$ in the outer bore, from the inner bore of $19.5 \mathrm{~mm} ; \mathrm{C}$ and $\mathrm{D}$ between $\mathrm{B}$ and $\mathrm{E}, 6.83 \mathrm{~mm}$ and $13.17 \mathrm{~mm}$ respectively from the inner bore. The radial node distribution is shown in Figure 1.

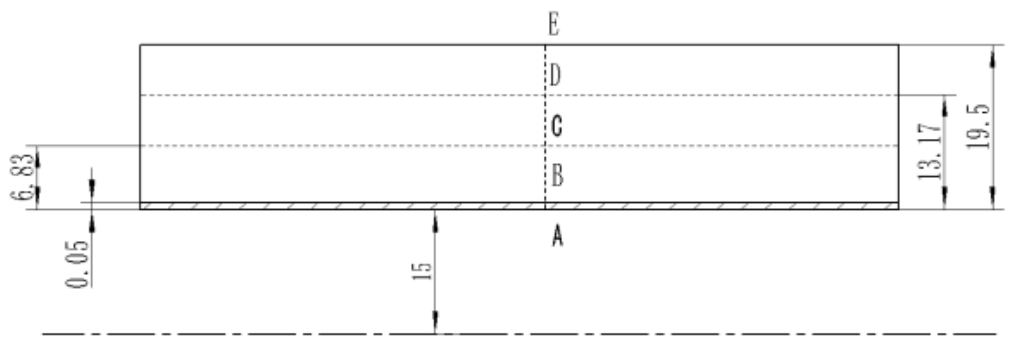

Fig.1. radial node distribution

The initial parameters for the thermal analysis of the body are shown in Table 1

Table 1 initial parameters of thermal analysis of body barrel

\begin{tabular}{ccccc}
\hline $\begin{array}{c}\text { Conduction coefficient } \\
/(\mathrm{W} / \mathrm{m} \cdot \mathrm{K})\end{array}$ & $\begin{array}{c}\text { Density } \\
/(\mathrm{kg} / \mathrm{m} 3)\end{array}$ & $\begin{array}{c}\text { Specific heat } \\
/(\mathrm{J} / \mathrm{kg} \cdot \mathrm{K})\end{array}$ & $\begin{array}{c}\text { launch speed } \\
(\text { Shoot } / \mathrm{min})\end{array}$ & $\begin{array}{c}\text { ambient temperature } \\
/(\mathrm{K})\end{array}$ \\
\hline 54.5 & 7200 & 502.4 & 300 & 293 \\
\hline
\end{tabular}

\section{Numerical simulation of barrel temperature field}

\section{Single shoot temperature field}

Single shoot barrel temperature distribution of the 3D map and inner bore temperature variation is shown in Figure 2, the figure $\mathrm{a}$ is the interior ballistic period, figure $\mathrm{b}$ is the aftereffect period, figure $\mathrm{c}$ is the whole period of ballistic, figure $\mathrm{d}$ is the inner bore temperature varying with time.

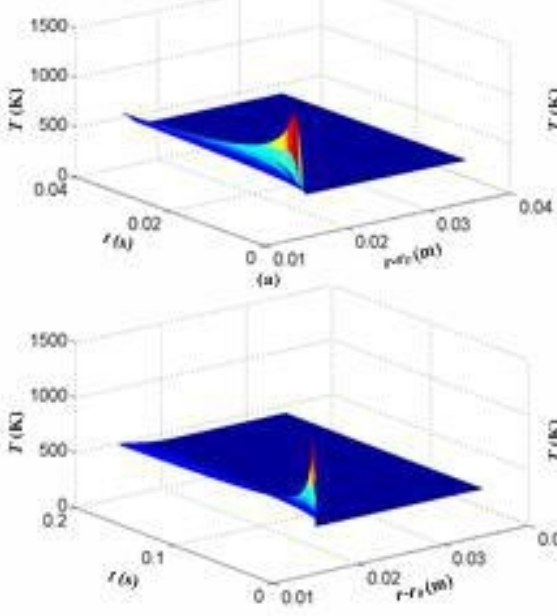

(e)

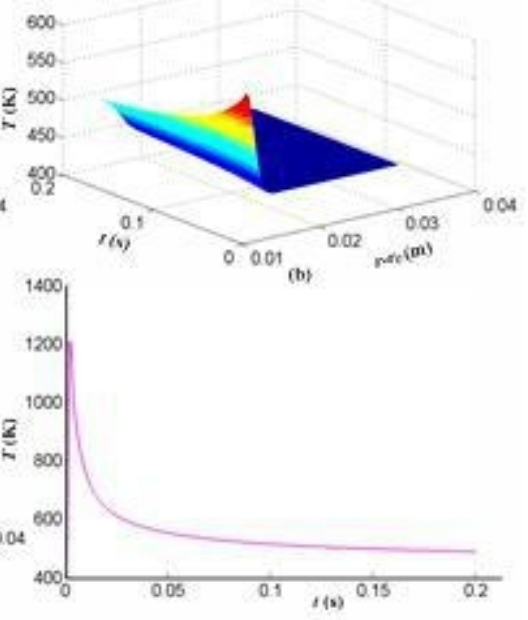

(d)

Fig. 2 the temperature distribution of single shot gun

The comprehensive effect of transfer coefficient and temperature in the high convection powder gas, obtained from the barrel of powder gas heat in the lot, the bore bore reached a high temperature in a very short period of time. The inner bore rose to the highest temperature value, close to $1200 \mathrm{~K}$ in the $1.68 \mathrm{~ms}$.

The temperature distribution along the radial direction at the time of maximum temperature during the single firing is shown in figure 3. 


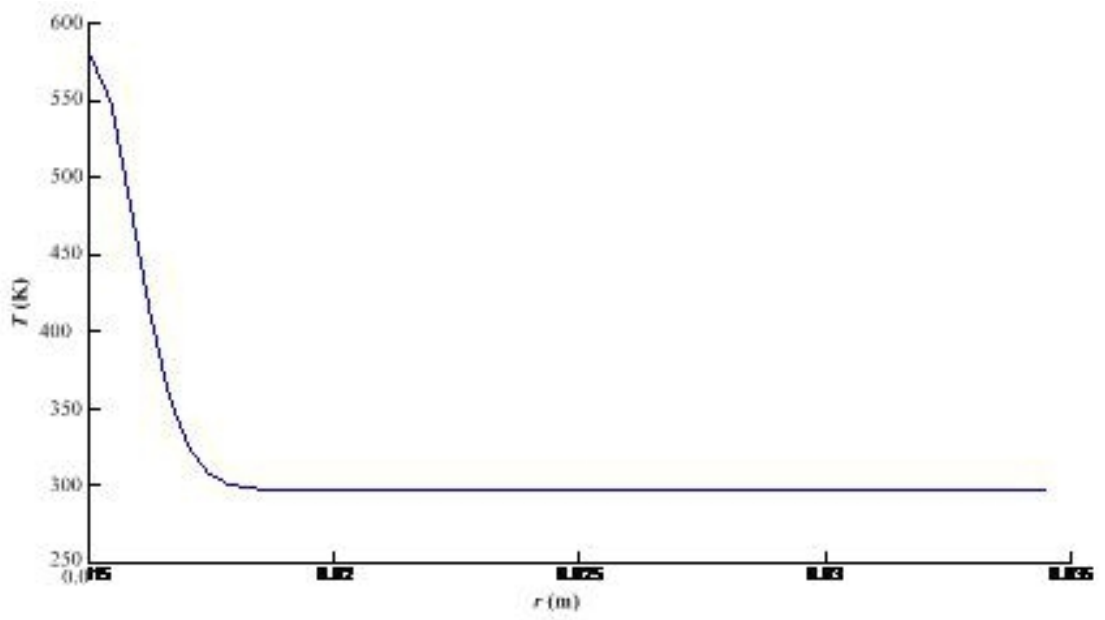

Fig. 3. temperature distribution along the radial direction

From Figure 3 we can see at the time the inner bore temperature is maximum, the heat obtained from the powder gas gathered in the inner bore, and the heat conduction resistance barrel under the influence of not timely conduction along the radial direction, the great temperature gradient along the radial direction, temperature rise has been 0 only from the bore about $2.5 \mathrm{~mm}$.

\section{Sequent shoot temperature field}

The firing indexes of $30 \mathrm{~mm}$ small caliber automatic gun is not less than 300 rounds per minute, and then this paper applies the emission rate of $0.2 \mathrm{~s} / \mathrm{shoot}$.

Figure 4 shows the 3D map of the temperature field, figure 5 and figure 6 show the temperature change rule along the radial point (A to $\mathrm{E}$ ).

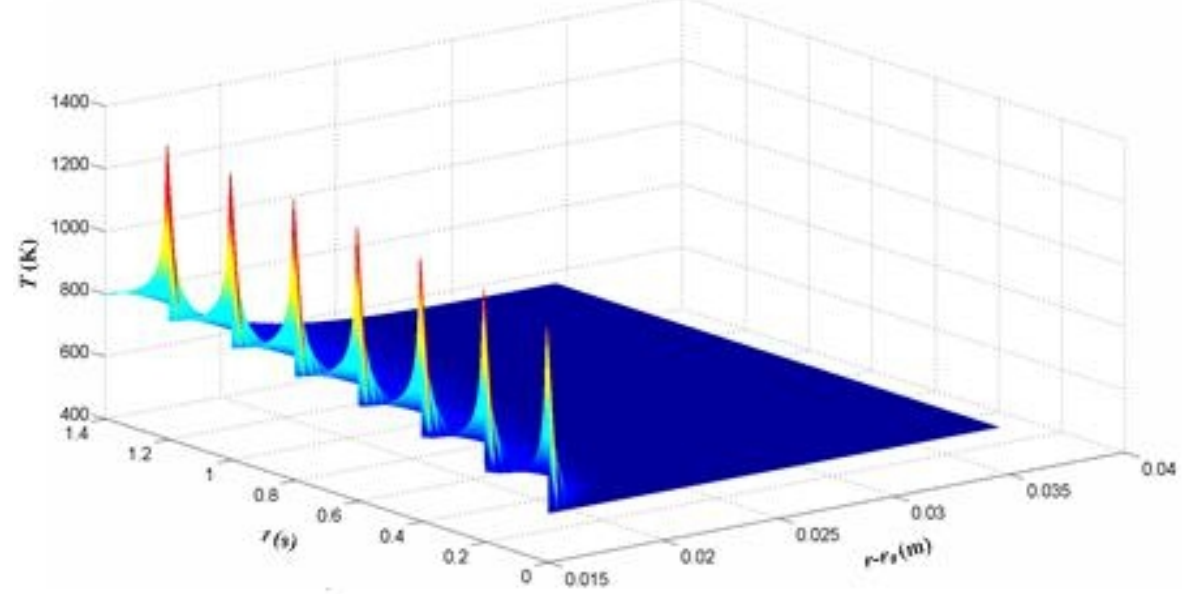

Figure .4. the 3D map of the temperature field

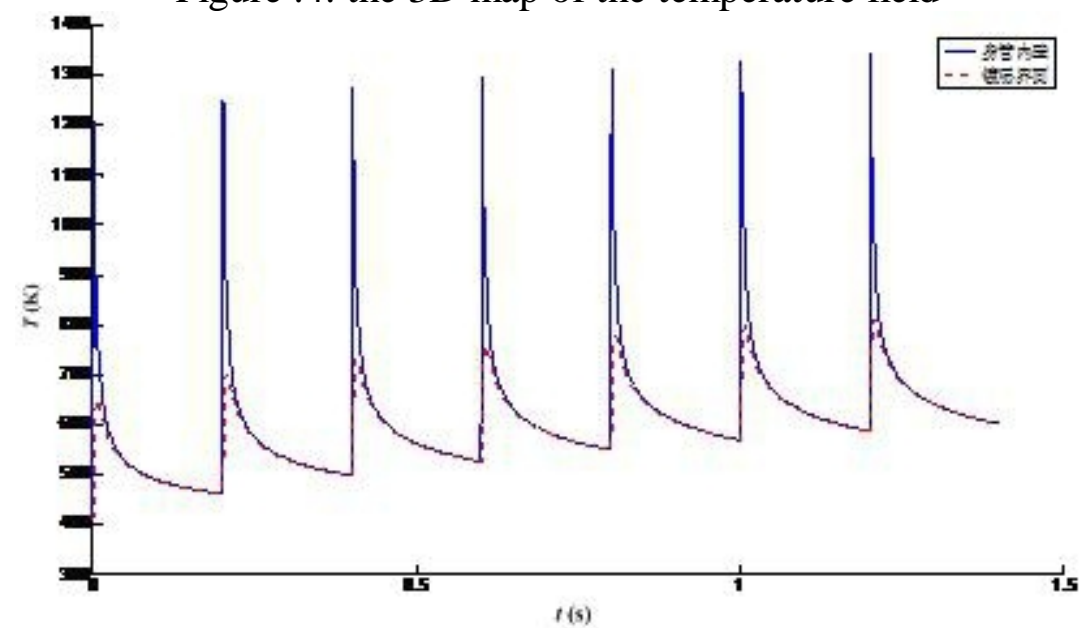

Figure. 5. the temperature change rule of chrome layer interface during sequent shoot 


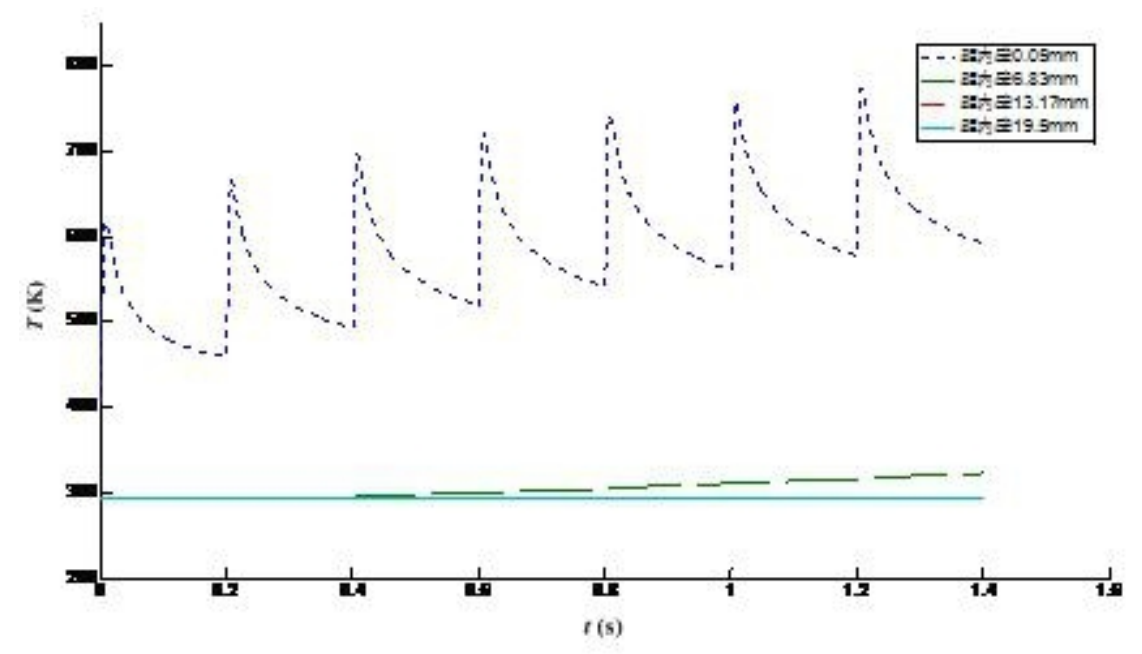

Figure. 6 . the temperature change rule during sequent shoot along radial point

The figure 4 to 6 show that the body barrel bore firing temperature when lifting appears periodically, every shot when the bore temperature variation and single firing intervals are basically the same, because the time is very short, heat can not pass out, gradually accumulated in bursts of process, the chamber bore temperature rise peak by hair, at the same time shooting the lowest temperature interval down also increased. In fact, from Figure 9 and figure 10 shows that the nodes in the B barrel on the one hand, also presents the temperature distribution of the same, the volatility is A, C, D, E node temperature is also presented by hair rising trend, but because from the bore distance, pulse characteristics of temperature was not obvious and linear slow growth trend; on the other hand, with the increase of amount of projectile, the peak temperature of the barrel of each node and the lowest temperature drop increases gradually decreased, as the heat transfer outside gradually, $\mathrm{C} \sim \mathrm{E}$ temperature increased with the increase of temperature, makes the body outer bore of barrel gradually reduced. In addition, we can see from Figure 9, the body barrel interface and the chamber bore compared to the peak of the rise phase is smaller, the changing trend of the two stage is basically the same.

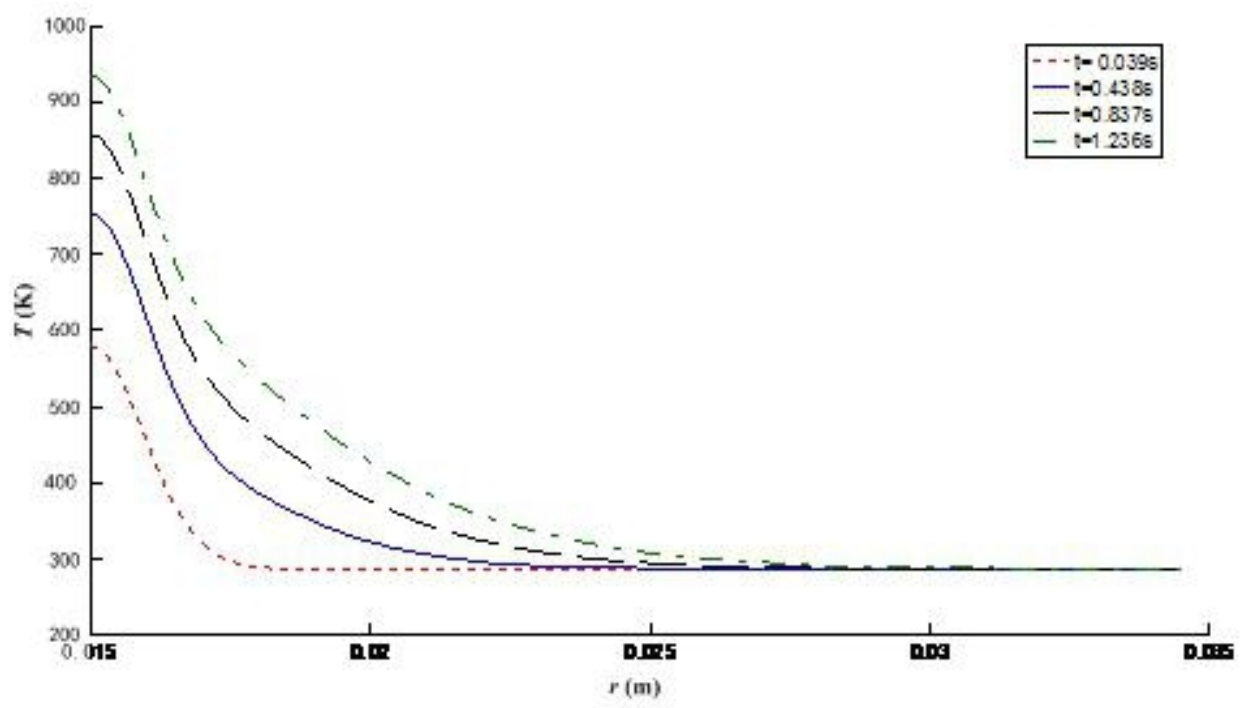

Fig. 7. radial distribution of temperature at different time

Figure7 shows that the temperature distribution along the barrel bore has the same form at the different time, the curve corresponding to the end time of the first, 3rd, 5th, 7th shots, permeability gathered from the inside to the outside surface of the inner bore slowly in the heat, which is affected by the barrel resistance, the temperature sensitivity of node radius increases gradually, as the nodes in the temperature change is slow, temperature rise is small. Also known from the figure, due to the chromium layer is very thin, only $50 \mu \mathrm{m}$, and the heat conductivity of the chromium material is higher 
than the body barrel material, so the temperature gradient near the interface between the chromium layer and the steel substrate is not obvious.

\section{Conclusions}

(1) The equation of temperature during the period and the aftereffect of gunpowder gas chamber is established on the basis of interior ballistic theory, and then the initial conditions of heat transfer is determined.

(2) The heat transfer coefficient is analyzed and the heat transfer boundary is determined during internal ballistic period on the basis of Mamontov hypothesis.

(3) Then, the heat transfer model was established according to the heat transfer theory, and the finite difference method was used to solve the model.

(4) Besides, 30mm small caliber automatic gun was taken as an example to analyze the change rule of temperature field distribution under the single and sequent firing conditions, and then the conclusion of steel substrate temperature gradient near the interface of the chromium layer is not obvious was obtained.

This paper provides a theoretical support for the ablation mechanism analysis and life prediction of small caliber gun barrel.

\section{References}

[1] TAN Le-bin, ZHANG Xiang-yan, GUAN Hong-gen. Artillery conspectus[M]. Beijing: Beijing Institute of Technology Press, 2005: 40-45(In Chinese).

[2] WU Bin, XIA Wei, TANG Yong. A review on thermal effects during the firing process and measures of their thermal control[J]. Acta Armamentarii, 2003, 24(4): 525-529(In Chinese).

[3] CHANG Lie-zhen, PAN Yu-tian, LI Kui-wu. Residual stress analysis of gun barrel with bilinear material model[J]. Acta Armamentarii, 2013, 34(4): 385-391(In Chinese).

[4] LI Ming-tao, CUI Wan-shan, YAO Zhe. Prediction method of barrel life based on inner side melting theory[J]. Journal of Gun Launch \& Control, 2008, (10): 5-8(In Chinese).

[5] Gao R P, Ye S. Improved adaptive pruning algorithm for least squares support vector regression[J]. Systems Engineering and Electronics, 2012, 23(3): 438-444.

[6] Chen M M. Projectile balloting attributable to gun tube curvature[J]. Shock and Vibration, 2010, 17(1): 39-53.

[7] KONG Guo-jie, ZHANG Pei-lin, QIAN Lin-fang. A new evaluation method for residual life of gun[J]. Journal of Ballistics, 2010, 22(3): 21-25(In Chinese). 